\title{
Prediction of City Saturated Load Based on Combined Logistic Model
}

\author{
Jing-min Wang \\ Department of Economic Management \\ North China Electric Power University \\ Baoding, China
}

\author{
Jie Zhang \\ Department of Economic Management \\ North China Electric Power University \\ Baoding, China
}

\begin{abstract}
Accurate load forecasting is the prerequisite for efficient resources distribution among the power supply, power grid and the users. Based on traditional logistic model, data accumulated generating method and grade differential format are used to design the logistic of grade difference format. In the meanwhile, another two factors affecting power load, GDP and population, are introduced into the traditional logistic model, and next the rate of diffusion is turned into function to form the logistic expand model .Finally, combined logistic model is constructed by the combination of the weights from the error criteria of the two models. Compared to traditional logistic model, subjective parameters and constant environment can be avoided in the model. Thus, it can better reflect the dynamic growth trend of future urban electric load. With the application of the model, urban electricity saturation consumption and the arrival time in Beijing have been predicted. The result shows that Beijing would enter the stage of power saturation in 2023 and the saturation electricity consumption would be 121.5 billion kWh.
\end{abstract}

Keywords-City Saturated Load; logistic model; grey theory; combination forecast.

\section{INTRODUCTION}

Power load forecast is based on the economic development, social conditions, weather and other historical data. It's essential to find the intrinsic link among the various factors and study the developing trends of power load to make scientific prediction in future. Accurate load forecasting is of great importance for realizing efficient utilization of resources among the power supply, power grid and the users. With the national economy enter into the new normal, China has entered the late stage of industrialization. According to the experience of the developed countries, the power load growth is slow or even stop under the influence of population, economy, resources and environment. Power load structure remains relatively stable, appears as a state of saturated [1-2]. Hence, the concept of saturation load, forecasting and research arises in urban power grid planning.

According to the analysis of the load development law of developed countries, load growth in one region or city often presents as the following trends: in the early stages of economic development, the growth of the power load is slow; with the rapid development of economy and society, it would promote the rapid development of power system load; but when the economy and society develop into a certain stage, power load growth would slow down and even stop growing with the limit of the regional energy structure, land resources, population scale, and environmental and resource conditions. In theory, "S" shaped curve can be used to show the development of the regional load, the whole development of power load growth stage can be divided into slow growth stage, rapid growth stage and saturation change phase, as shown in Fig. 1.

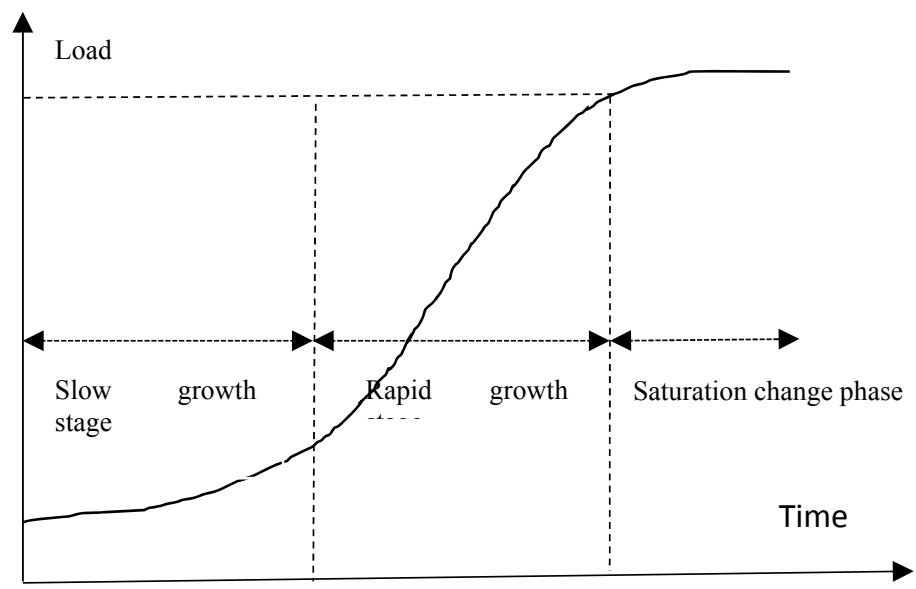

Fig. 1. Saturated logistic growth curve

\section{Establish the COMBINED LOGISTIC MODEL}

Logistic curve is a common " $\mathrm{S}$ " type curve which was derived from the study of biomass. In many fields such as economy, society, population, the development characteristics were also consistent with the law of curve [3-4]. Traditional logistic model uses three parameters of nonlinear differential equation to reflect the dependent variable changes over time, the accuracy of the parameter estimates are the main influencing factors for prediction [5-6]. Firstly, the article considers the features of traditional logistic model and establishes the logistic expand model with the power load growth affected by main macroeconomic factors. Secondly, by using the gray accumulated generating method and the exact format of the gray model, the logistic model of grade difference format is established. In order to use of the advantages of the above two models better and improve the accuracy of prediction, a combination forecast model of saturated load power is built with the weights of a standard deviation. This model can analysis the long-term change rule of urban power load which is affected by various factors and the change trend of the urban power load saturation. 


\section{A. The logistic expand model}

The traditional logistic model expressed as follows:

$$
\mathrm{N}=\frac{1}{k+a e^{b t}}(k>0, a>0, b<0)
$$

Where, $t$ is a set of time series values; $\mathrm{N}$ refers to city power load value at timet; $k$ indicates city power saturation factor, the smaller the $\mathrm{k}$ value, the greater the power saturation values; $b$ indicates city power growth factor, the smaller the absolute value of $b$, the more smoothly logistic curve moves.

The change of the urban power load is influenced by economic development, population change, industrial structure and other factors [7].it is concentrated considering the main influence factors for the independent variables directly, and doesn't retain the characteristics traditional logistic model present S-form as dependent variable changing over time in previous studies. Through factor analysis and correlation analysis of each variable between similar factors, GDP and population are selected as affecting factors for urban power load. The urban power load growth factor measuring model is as follows:

$$
b=\beta_{1} \ln (\mathrm{GDP})+\beta_{2} \ln (\mathrm{POP})
$$

Put the formula 2 into the formula 1 and get logistic expand prediction model:

$$
\mathrm{N}=\frac{1}{k+a * \exp \left(\left(\beta_{1} \ln (\mathrm{GDP})+\beta_{2} \ln (\mathrm{POP})\right) t\right)}
$$

\section{B. The logistic of grade difference format}

Due to various factors, power load historical data has a lot of randomness. Parameter estimates tend to have large errors with regression model of historical data directly. In order to obtain more accurate and objective parameters, this paper reference gray theory accumulated generating method to deal with the historical data and use grade difference format to correct the logistic model. Let the sequence of power load historical data after taking the reciprocal is as follow:

$$
\begin{gathered}
x^{(0)}=\left\{x^{(0)}(t) \mid x^{(0)}(t) \geq 0, t=1,2, \cdots, n\right\} \\
x^{(0)}(t)=k+a e^{b t}
\end{gathered}
$$

The sequence of once accumulation is as follow:

$$
\begin{aligned}
& x^{(1)}=\left\{x^{(1)}(t) \mid x^{(1)}(t) \geq 0, t=1,2, \cdots, n\right\} \\
& x^{(1)}(t)=\sum_{i=1}^{t} x^{(0)}(i)=k t+\frac{a}{1-e^{b}}-\frac{a e^{b t}}{1-e^{b}}
\end{aligned}
$$

Calculated differential to get:

$$
\frac{d x^{(1)}(t)}{d t}+\lambda x^{(1)}(t)+\mu t=\beta
$$

Where, $\lambda=-b, \mu=k b, \beta=k+\frac{a b}{1-e^{b}}$

In order to reduce the error, this paper use comprehensive front and rear differential mean value theorem format, the calculation is as follow:

$$
x^{(0)}(t)=p_{1} x^{(1)}(t+1)+p_{2} x^{(1)}(t)+p_{3} t+p_{4} f(t)+p_{5}
$$

Where, $f(t)=\frac{\left(1+(-1)^{t-1}\right)}{2}, \quad p_{1}=1, \quad p_{2}=-e^{-2 b}$,

$p_{3}=k\left(e^{-2 b}-1\right){ }^{\prime} \quad p_{4}=\zeta$,

$p_{5}=k\left(e^{-2 b}+1\right)+\left(a+k+\left(a e^{b}\right) e^{-2 b}(1+\zeta)\right)$

By computer simulation to get the $p_{2}$ value, and use $p_{2}=-e^{-2 b}$ to solve the $b$ value. Parameter $a$ and $k$ are obtained through linear fitting depending on $x^{(0)}(t)=k+a e^{b t}$, Model result is as follows:

$$
\hat{\mathrm{N}}=\frac{1}{\hat{k}+\hat{a} e^{\hat{b t}}}
$$

\section{The combined logistic model}

Logistic expand model takes the main influencing factors of the city power load into account, and can objectively reflect the load change when the other main factors change. However, we should first predict the various factors when this prediction model for urban power load is used in the long-term forecast. Different prediction accuracy would cause knock-on effect on the city power load forecast. The logistic model of grade difference format is a time series essentially. It reflects the changing trend from the comprehensive level, but does not reflect the impact of other factors. Combination forecasting model can make full use of information independent of each prediction method contained in. So this paper would establish combination forecasting model based on the above two models. The core is to determine the weight of each single prediction method. As the forecast results of each model are known, this article adopts the minimum variance standard deviation to determine combination weights.

Suppose standard deviation and the weight of the i-th prediction models are $\delta_{i}, \quad \omega_{i}$ and $\omega_{i}=\left(\delta-\delta_{i}\right) / \sum_{i=1}^{2} \delta_{i}$. Combined logistic model is as follow:

$$
N_{t}=\omega_{1} N_{t}^{1}+\omega_{2} N_{t}^{2}
$$

Where, $N_{t}, N_{t}^{1}, N_{t}^{2}$ represents the predictive value of combined model, logistic expand model and logistic model of grade difference format in year $t$ respectively.

\section{THE PREDICTION OF BEIJING SATURATION POWER LOAD}

From the Beijing Statistical Yearbook, historical data of Beijing about electricity consumption, GDP and population from 1978 to 2014 are obtained. The parameters of logistic expand model is solved by nonlinear regression of 1 stopt:

$$
\begin{gathered}
\mathrm{N}^{1}=\frac{1}{8.24 \times 10^{-8}+1.21 \times 10^{-6} \times e^{b^{*}(t-1977)}} \\
b=-0.015 \times \ln (\mathrm{GDP})+0.006 \times \ln (\mathrm{POP}) \\
R^{2}=0.998, F=7580.43, \delta_{1}=105306.08 .
\end{gathered}
$$

It shows that the model has high accuracy and factors can explain $99 \%$ of the Beijing power load changes. 
The parameters of logistic model of grade difference format is solved by MATLAB software programming, the result is as follows:

$$
\begin{gathered}
\mathrm{N}^{2}=\frac{1}{5.11 \times 10^{-8}+2.52 \times 10^{-6} \times e^{-0.102 \times(t-1977)}} \\
R^{2}=0.995, F=3267.1, \delta_{2}=199419.11
\end{gathered}
$$

The weight of combination forecast model can be get based on the error standard deviation of the above two model: $w_{1}=0.654, w_{2}=0.346$.

Therefore, the combination forecast model formula is:

$$
N_{t}=0.654 \times N_{t}^{1}+0.346 \times N_{t}^{2}
$$

\begin{tabular}{|c|c|c|c|c|c|c|c|}
\hline \multirow{2}{*}{ Year } & \multirow{2}{*}{ Actual value } & \multicolumn{2}{|c|}{ Logistic expand model } & \multicolumn{2}{|c|}{ Logistic model of grade difference format } & \multicolumn{2}{|c|}{ Combined logistic model } \\
\hline & & predicted value & relative error & predicted value & relative error & predicted value & relative error \\
\hline 2004 & 51.32 & 51.64 & $0.63 \%$ & 51.28 & $-0.08 \%$ & 51.51 & $0.38 \%$ \\
\hline 2005 & 57.05 & 55.99 & $-1.87 \%$ & 55.24 & $-3.18 \%$ & 55.73 & $-2.32 \%$ \\
\hline 2006 & 61.16 & 60.63 & $-0.87 \%$ & 59.38 & $-2.91 \%$ & 60.19 & $-1.58 \%$ \\
\hline 2007 & 66.70 & 65.96 & $-1.11 \%$ & 63.69 & $-4.52 \%$ & 65.17 & $-2.29 \%$ \\
\hline 2008 & 68.97 & 70.37 & $2.02 \%$ & 68.15 & $-1.19 \%$ & 69.60 & $0.91 \%$ \\
\hline 2009 & 73.91 & 74.33 & $0.56 \%$ & 72.76 & $-1.57 \%$ & 73.78 & $-0.18 \%$ \\
\hline 2010 & 80.99 & 79.10 & $-2.33 \%$ & 77.49 & $-4.33 \%$ & 78.54 & $-3.02 \%$ \\
\hline 2011 & 82.17 & 83.60 & $1.74 \%$ & 82.31 & $0.17 \%$ & 83.15 & $1.20 \%$ \\
\hline 2012 & 87.43 & 87.32 & $-0.12 \%$ & 87.22 & $-0.24 \%$ & 87.29 & $-0.16 \%$ \\
\hline 2013 & 91.31 & 90.96 & $-0.39 \%$ & 92.18 & $0.96 \%$ & 91.38 & $0.08 \%$ \\
\hline 2014 & 93.70 & 94.06 & $0.38 \%$ & 97.18 & $3.70 \%$ & 95.14 & $1.53 \%$ \\
\hline
\end{tabular}

TABLE I. THE COMPARISON BETWEEN ACTUAL VALUE AND PREDICTED VALUE OF BEIJING POWER CONSUMPTION FROM 2004 TO 2014(UNIT: BILLION KWH)

The comparison between actual value and predicted value of Beijing electricity consumption from 2004 to 2014 are shown in table I. The maximum relative error of the three models were $2.33 \%, 4.52 \%, 3.02 \%$ and the minimum relative error were $0.12 \%, 0.08 \%, 0.08 \%$ respectively. Three model has higher prediction accuracy, but the combined logistic model can better comprehend the advantages of other two models. So the combined logistic model is used to predict the future city electricity power consumption of Beijing, the predicted results is in table II.

\begin{tabular}{|c|c|c|c|c|c|c|}
\hline \multirow[t]{2}{*}{ Year } & \multicolumn{2}{|c|}{$\begin{array}{l}\text { Logistic expand } \\
\text { model }\end{array}$} & \multicolumn{2}{|c|}{$\begin{array}{l}\text { Logistic model of } \\
\text { grade difference } \\
\text { format }\end{array}$} & \multicolumn{2}{|c|}{$\begin{array}{c}\text { Combined logistic } \\
\text { model }\end{array}$} \\
\hline & $\begin{array}{c}\text { predicted } \\
\text { value }\end{array}$ & $\begin{array}{c}\text { growth } \\
\text { rate }\end{array}$ & $\begin{array}{c}\text { predicted } \\
\text { value }\end{array}$ & $\begin{array}{c}\text { growth } \\
\text { rate }\end{array}$ & $\begin{array}{c}\text { predicted } \\
\text { value }\end{array}$ & $\begin{array}{c}\text { growth } \\
\text { rate }\end{array}$ \\
\hline 2015 & 97.26 & $3.40 \%$ & 102.17 & $5.14 \%$ & 98.96 & $4.02 \%$ \\
\hline 2016 & 99.97 & $2.79 \%$ & 107.14 & $4.87 \%$ & 102.45 & $3.53 \%$ \\
\hline 2017 & 102.40 & $2.42 \%$ & 112.06 & $4.60 \%$ & 105.74 & $3.21 \%$ \\
\hline 2018 & 104.55 & $2.10 \%$ & 116.91 & $4.33 \%$ & 108.82 & $2.92 \%$ \\
\hline 2019 & 106.45 & $1.82 \%$ & 121.67 & $4.07 \%$ & 111.71 & $2.65 \%$ \\
\hline 2020 & 108.13 & $1.58 \%$ & 126.31 & $3.81 \%$ & 114.41 & $2.42 \%$ \\
\hline 2021 & 109.61 & $1.37 \%$ & 130.81 & $3.56 \%$ & 116.93 & $2.21 \%$ \\
\hline 2022 & 110.91 & $1.19 \%$ & 135.16 & $3.32 \%$ & 119.29 & $2.02 \%$ \\
\hline 2023 & 112.06 & $1.04 \%$ & 139.34 & $3.09 \%$ & 121.49 & $1.84 \%$ \\
\hline 2024 & 113.08 & $0.90 \%$ & 143.34 & $2.87 \%$ & 123.53 & $1.69 \%$ \\
\hline 2025 & 113.97 & $0.79 \%$ & 147.16 & $2.66 \%$ & 125.44 & $1.54 \%$ \\
\hline 2026 & 114.76 & $0.69 \%$ & 150.79 & $2.46 \%$ & 127.21 & $1.41 \%$ \\
\hline 2027 & 115.46 & $0.61 \%$ & 154.22 & $2.28 \%$ & 128.85 & $1.29 \%$ \\
\hline 2028 & 116.08 & $0.54 \%$ & 157.45 & $2.10 \%$ & 130.38 & $1.18 \%$ \\
\hline 2029 & 116.63 & $0.47 \%$ & 160.49 & $1.93 \%$ & 131.79 & $1.08 \%$ \\
\hline 2030 & 117.12 & $0.42 \%$ & 163.34 & $1.77 \%$ & 133.09 & $0.99 \%$ \\
\hline
\end{tabular}

TABLE II. THE PREDICTED VALUE OF BEIJING ELECTRICITY CONSUMPTION FROM 2015 TO 2030 (UNIT: BILLION KWH)

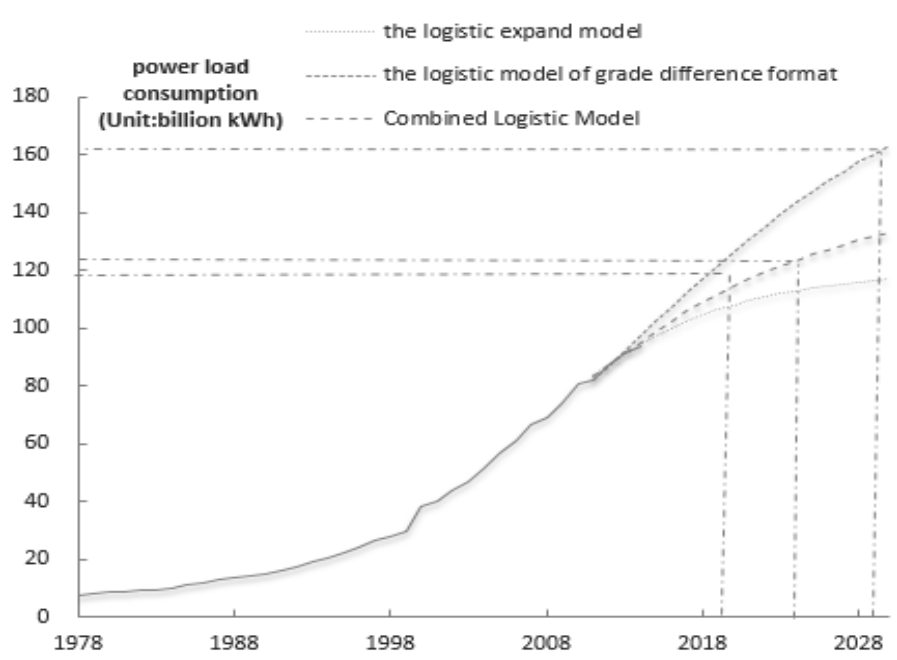

Fig. 2.Prection of the city saturation load

Reference for related studies, as long as the growth rate of electricity consumption is less than $2 \%$, it indicates that the city electricity consumption has entered the saturation stage [8-9]. Three model predicted results show that the growth rate of Beijing electricity consumption is slowing from 2015. The logistic expand speed down rapidly and expects that Beijing would enter the saturation stage of development in 2019, whose saturated power consumption is 106.45 billion $\mathrm{kWh}$. Predicted results of the logistic model of grade difference format grow most gently, the beginning of saturation stage is in 2029 and saturated power consumption is 160.49 billion $\mathrm{kWh}$. The growth rate of combined logistic model is moderate. Since 2023, Beijing would enter saturation stage of power consumption and its saturated power consumption is 121.49 billion kWh (Fig.2). 


\section{CONCLUSIONS}

Based on the development of power load in accordance with logistic curve change rule, logistic model of grade differential format is set up by combining with the accumulation generation sequence of grey theory of differential format. This method improves the integrated use of historical data and has strong anti-interference ability. Economy and population are the main factors which can effect on the power consumption, by establishing logistic expand model and functioning the parameters of the model are functional according to the factors. This paper analyzes the degree of changes in the rate of power load with the other factors change. Combination logistic model for the weight of error standard deviation is established. This model combines the advantages of two kinds of prediction model and improves the prediction accuracy. Finally, by using the model to forecast the future city power consumption in Beijing, what results that the paper gets show that, the power consumption of Beijing would be 121.49 billion kWh by 2023 and then Beijing would enter into power saturation stage.

\section{REFERENCES}

[1] Cui Kai, Li Jingru, Liu Haibo, et al. "City's power planning methods at the stage of load saturation and its application in Jinan power grid". Power System Technology, vol. 31, no. S2, pp. 131-134, Dec 2007. (In Chinese)

[2] Cui Kai, Li Jingru, Zhao Biao, et al. "Research on city saturated load and its forecast methods". Electric Power Technologic Economics, vol. 20, no. 6, pp. 34-38, Dec 2008. (In Chinese)

[3] Yang K. "Basic properties of mathematical population models". Journal of Biomathematics, vol. 17, no. 2, pp. 129-142,2002.

[4] MA Xiaodong. "Research on saturated load and goal grid frame-work in Suzhou City". Nanjing:Southeast China University,2006. (In Chinese)

[5] G. Fan, "A method to estimating the parameters of general Logistic curve," Journal of Liaoning Normal University, vol. 32, no. 4, pp. 426-429, Dec. 2009. (In Chinese)

[6] Yuan Yanhua. "comparisons of parameter estimation on logistic model". Journal of Heilongjiang institute of science \& technology, vol. 18, no. 4, pp: 474-477, 2008. (In Chinese)

[7] Wang Fangdong, Lin Han, Li Weidong. "Research on saturated load macroscopically forecast based on saturated situation analysis of economy curve".East China Electric Power, vol. 38, no. 10, pp: 1486-1491, 2010.(In Chinese)

[8] Wang Wei, Fang Tingting. "The application of per person electricity consumption method in saturation load forecasting". Power Demand Side Management, vol. 20, no. 6, pp: 34-38, 2012.(In Chinese)

[9] Wang Fangdong, Lin Han, Li Weidong, et al. "Research on saturated load macroscopically forecast based on saturated situation analysis of economy curve". East China Electric Power, vol. 38, no. 10, pp:1486-1491,2010.(In Chinese) 